\title{
ARTICLE
}

\section{Is low-protein diet a possible risk factor of malnutrition in chronic kidney disease patients?}



Chronic kidney disease (CKD) is becoming increasingly widespread in the world. Slowing its progression means to prevent uremic complications and improve quality of life of patients. Currently, a low-protein diet (LPD) is one of the tools most used in renal conservative therapy but a possible risk connected to LPD is protein-energy wasting. The aim of this study is evaluate the possible correlation between LPD and malnutrition onset. We enrolled 41 CKD patients, stages IIIb/IV according to K-DIGO guidelines, who followed for 6 weeks a diet with controlled protein intake (recommended dietary allowance $0.7 \mathrm{~g}$ per kilogram Ideal Body Weight per day of protein). Our patients showed a significant decrease of serum albumin values after 6 weeks of LDP (T2) compared with baseline values (TO) $(P=0.039)$, whereas $C$-reactive protein increased significantly (T0 versus $\mathrm{T} 2 ; P=0.131)$. From body composition analysis, a significant impairment of fat-free mass percentage at the end of the study was demonstrated (T0 versus T2; $P=0.0489$ ), probably related to total body water increase. The muscular mass, body cell mass and body cell mass index are significantly decreased after 6 weeks of LDP (T2). The phase angle is significantly reduced at the end of the study compared with basal values (T0 versus T2; $P=0.0001$, and T1 versus T2; $P=0.0015$ ). This study indicated that LPD slows down the progression of kidney disease but worsens patients' nutritional state.

Cell Death Discovery (2016) 2, 16026; doi:10.1038/cddiscovery.2016.26; published online 9 May 2016

Chronic kidney disease (CKD) represents a major problem of public health and its evolution in end-stage renal disease requires renal replacement therapy (hemodialysis, peritoneal dialysis (PD) or transplantation). Worldwide, CKD incidence is high. ${ }^{1}$ For example, CKD incidence, stages 1 to 4 , in USA population (NHANES Study) is $13.1 \%$. CKD is more frequent among older individuals and subjects with hypertension and diabetes, suggesting that CKD needs to have a central part in future public health planning. ${ }^{2}$ In 2007, average inpatient cost for the first month of dialysis in the US was $\$ 9846$ per Medicare member and \$22 841 per employer group health plan member. ${ }^{3}$ According to the United States Renal Data System database, in 2010, the total expenses per patient for hemodialysis was $\$ 87561$ compared with $\$ 66751$ for PD. ${ }^{3}$ Epidemiological data collected in Italy suggest that the prevalence of CKD in male subjects is $8.1 \%$ and in female subjects is 7.8\%; these values are lower in comparison with European and non-European countries, probably because of the Mediterranean-style food. ${ }^{4-7}$ Thus, slowing the progression of CKD is necessary not only to improve the quality of life of uremic patients but also to reduce the significant impact that this disease has on public health costs.

In the last 100 years, CKD patient management of restriction of dietary daily protein intake, has a central role. ${ }^{8}$ During the 1960 s, for the first time, Giovannetti and Maggiore ${ }^{9}$ set the stage for diet therapy treatments currently used in CKD patients. However, the role of low-protein diet (LPD) in the progression of CKD remains controversial with discrepancies between various studies performed. ${ }^{8,10}$ Despite the obvious benefits of protein restriction (such as the reduction of accumulation of nitrogenous wastes and metabolic disturbances, commonly associated with CKD) several studies have demonstrated that especially very LPDs could cause deterioration in the nutritional status of CKD patients. ${ }^{10}$ Menon and coworkers ${ }^{11}$ compared LPD with very LPD supplemented with keto acids and amino acids and demonstrated that both diets had no effects on the progression of kidney disease but increased the long-term risk of death.

In CKD patients, protein-energy wasting is a frequent condition, characterized by low serum levels of albumin or transthyretin, sarcopenia and weight loss. Protein-energy wasting is strongly related to mortality in CKD patients. ${ }^{12}$ A 10 -year cohort study in 206 hemodialysis patients showed that serum albumin level was a stronger predictor of mortality, more than inflammatory markers or intima-media thickness of the common carotid artery. ${ }^{13}$ In CKD population, surrogates of over-nutrition, for instance obesity or hyperlipidemia, seem to be associated with increased survival; this phenomenon is now acknowledged as 'reverse epidemiology'. ${ }^{14}$

The aim of this study is to evaluate whether 6 weeks of lowprotein diet has impact on body composition, inflammatory markers and progression of CKD in nephropathic patients (stage IIIb/IV according to K-DIGO guidelines).

Furthermore, we measured for the first time erythrocyte glutathione S-transferase (e-GST), a well-characterized cellular detoxifying enzyme, and erythrocyte catalase (e-CAT), a protecting enzyme against oxidative stress in CKD patients enrolled in LPD protocol.

In previous studies, e-GST was already considered a potential biomarker of blood toxicity and adequacy of the dialytic treatments in nephropathic patients. ${ }^{15-17}$

\footnotetext{
${ }^{1}$ Department of Systems Medicine, Hypertension and Nephrology Unit, University of Rome 'Tor Vergata', Rome, Italy; ${ }^{2} \mathrm{Haemodyalisis} \mathrm{Service,} \mathrm{'Nuova} \mathrm{Clinica} \mathrm{Annunziatella',} \mathrm{Rome,}$ Italy; ${ }^{3}$ Department of Biomedicine and Prevention, Division of Clinical Nutrition and Nutrigenomic, University of Rome 'Tor Vergata', Rome, Italy; ${ }^{4}$ Nutrition Service, 'Nuova Clinica Annunziatella', Rome, Italy and ${ }^{5}$ Department of Chemical Sciences and Technologies, University of Rome 'Tor Vergata', Rome, Italy. 


\section{RESULTS AND DISCUSSION}

All the enrolled 41 subjects completed the study, and all their data were eligible for the analysis. In Table 1 are summarized the demographic and clinical parameters of CKD patients at the enrollment into the study. As expected, we observed a statistically significant reduction, in all time-points, of creatinine and azotemia values, as reported in Table 2.

Moreover, we observed a significant decrease of serum albumin values after 6 weeks of LPD (T2) compared with baseline values (T0) $(P=0.039)$. At the same time-points, total proteins were significantly lower at T1 ( 3 weeks of LPD) and T2 ( 6 weeks of LPD) with respect to T0 $(P<0.0001)$ (Table 2$)$. Inversely, C-reactive protein (CRP) at the end of the study increased significantly compared with start point values (T0 versus T2; $P=0.0131$ ).

Regarding lipid profile (total cholesterol, high-density lipoprotein cholesterol, low-density lipoprotein cholesterol and triglyceride), we observed changes statistically significant only for total cholesterol and low-density lipoprotein cholesterol; in particular, we measured a reduction at $\mathrm{T} 1$ for both parameters (Table 2), as previously reported. ${ }^{18}$

Table 1. Epidemiological parameters of chronic kidney disease (CKD) patients

\begin{tabular}{lc}
\hline Patients characteristics & \\
\hline Number of patients & 41 \\
Gender (male/female) & $(22 / 19)$ \\
Mean age (years) & $73 \pm 14$ \\
Hypertension (\%) & $28(68)$ \\
Diabetes mellitus (\%) & $11(27)$ \\
Dyslipidemia (\%) & $12(29)$ \\
& \\
Likely underlying renal disease: & $13(32)$ \\
a) Chronic glomerulonephritis (\%) & $24(58)$ \\
b) Nephroangiosclerosis (\%) & $1(2)$ \\
c) Chronic pyelonephritis and interstitial nephropathy (\%) \\
d) ADPKD (\%) \\
e) Other causes (\%) & $1(2)$ \\
\hline aDPPKD: Autosomal dominant polycystic kidney disease. & $2(\sim 5)$ \\
\hline
\end{tabular}

In addition, we found a significant lowering of albuminuria and azoturia in every time-point (Table 2). The systolic blood pressure decreased significantly at $\mathrm{T} 1$ and $\mathrm{T} 2$ time-points compared with enrollment time (TO), as reported in Table 2, but we did not observe any changes in diastolic pressure.

In Table 3, we summarized the body composition parameters observed in all time-points of the study. In particular, we underlined a significant reduction of anthropometric values of weight and body mass index (BMI) with respect to basal values (Table 3). In terms of body composition parameters, we saw a significant increase of total body water (expressed in \% and in Liters) at T1 (3 weeks of LPD) and T2 (6 weeks of LPD) compared with the start values of the study (T0). Consequently, we detected a significant impairment of fat-free mass percentage at the end of the study (T0 versus T2; $P=0.0489$ ). These data are probably because of the increase of total body water observed.

The muscular mass, expressed in $\mathrm{Kg}$ and percentage, is significantly decreased after 6 weeks of LDP (T2) to baseline value (Table 3). Interestingly, we showed a progressive and significant reduction of body cell mass (BCM), in $\mathrm{kg}$ and in percentage, and $\mathrm{BCM}$ index (BCMI) at $\mathrm{T} 0$ versus $\mathrm{T} 2$ and $\mathrm{T} 1$ versus $\mathrm{T} 2$ (Table 3). These parameters are expression of metabolically active mass and consequently indirect indexes of malnutrition state of the patients. The ratio between extracellular mass (ECM) and BCM is used to identify fluid imbalance or malnutrition. In normal subjects, this parameter is in the range $0.85-1.00 .^{19}$ The index cutoffs used to identify the malnutrition status of patients are: 1.11.3 for a moderate to poor nutritional condition and $\geq 1.3$ for a very poor nutritional status. ${ }^{20}$ In our study, at baseline, the patients showed a mean value of ECM/BCM ratio of $1.1 \pm 0.4$ indicating a poor nutritional condition. This value increased significantly at T1 $(P=0.04)$ and at T2 $(P=0.04)$ showing that LPD aggravated the malnourishment of CKD patients (Table 3 ).

The phase angle (PA) is significantly reduced at the end of the study compared with basal values (T0 versus T2; $P=0.0001$, and T1 versus T2; $P=0.0015)$; this parameter is a negative prognostic factor for survival as previously demonstrated in the literature. ${ }^{21,22}$

The e-GST levels (Figure 1a) and e-CAT levels (Figure 1b) remained stable during the experimental period, before starting the LPD till 6 weeks of LPD, in which patients were monitored for these enzymatic activities.

Table 2. Laboratory parameters and blood pressure at baseline (T0), after 3 weeks (T1) and 6 weeks (T2) of low-protein diet

\begin{tabular}{|c|c|c|c|c|c|c|}
\hline Laboratory findings & TO & $T 1$ & $T 2$ & T0 versus $T 1, P$ & T0 versus $T 2, P$ & T1 versus $T 2, P$ \\
\hline Creatinine (mg/dl) & $3.3 \pm 0.5^{a}$ & $2.5 \pm 0.1^{\mathrm{a}}$ & $2.3 \pm 0.2^{a}$ & 0.0001 & $<0.001$ & 0.0002 \\
\hline $\mathrm{eGFR}^{\mathrm{b}}(\mathrm{ml} / \mathrm{min})$ & $23 \pm 1^{\mathrm{a}}$ & $26 \pm 2^{a}$ & $29 \pm 2^{\mathrm{a}}$ & 0.0003 & 0.0019 & $<0.0001$ \\
\hline Azotemia (mg/dl) & $83(43-207)^{c}$ & $74(35-216)^{c}$ & $66(37-182)^{c}$ & 0.0026 & 0.0017 & n.s. \\
\hline Albumin (g/dl) & $4.1 \pm 0.1^{\mathrm{a}}$ & $4.1 \pm 0.1^{\mathrm{a}}$ & $4.0 \pm 0.1^{\mathrm{a}}$ & n.s. & 0.039 & n.s. \\
\hline Total protein $(\mathrm{g} / \mathrm{dl})$ & $7.3 \pm 0.1^{\mathrm{a}}$ & $6.9 \pm 0.1^{\mathrm{a}}$ & $6.9 \pm 0.1^{\mathrm{a}}$ & $<0.0001$ & $<0.0001$ & n.s. \\
\hline $\mathrm{CRP}^{\mathrm{b}}(\mathrm{mg} / \mathrm{l})$ & $1(0-68)^{c}$ & $1(0-66)^{c}$ & $2(0-69)^{c}$ & n.s. & 0.0131 & n.s. \\
\hline Potassium (mEq/l) & $4.6 \pm 0.1^{a}$ & $4.4 \pm 0.1^{a}$ & $4.5 \pm 0.1^{a}$ & 0.030 & n.s. & n.s. \\
\hline Phosphorus (mg/dl) & $4.0(3.0-5.8)^{c}$ & $3.8(2.9-6.2)^{c}$ & $3.6(2.5-5.5)^{c}$ & n.s. & 0.001 & 0.04 \\
\hline Sodium $(\mathrm{mEq} / \mathrm{l})$ & $139 \pm 1^{\mathrm{a}}$ & $138 \pm 1^{\mathrm{a}}$ & $138 \pm 1^{\mathrm{a}}$ & n.s. & n.s. & n.s. \\
\hline Calcium (mg/dl) & $9.7(7.8-11.0)^{c}$ & $9.6(6.5-10.5)^{c}$ & $9.3(7.4-10.6)^{c}$ & 0.0003 & n.s. & 0.0026 \\
\hline Total cholesterol (mg/dl) & $177(85-293)^{c}$ & $164(91-335)^{c}$ & $164(98-282)^{c}$ & 0.0025 & n.s. & n.s. \\
\hline LDL cholesterol (mg/dl) & $104(38-213)^{c}$ & $96(41-238)^{c}$ & $102(41-196)^{c}$ & 0.0118 & n.s. & n.s. \\
\hline HDL cholesterol (mg/dl) & $51(32-88)^{c}$ & $49(30-90)^{c}$ & $47(18-76)^{\mathrm{c}}$ & n.s. & n.s. & n.s. \\
\hline Triglycerides (mg/dl) & $133 \pm 7^{a}$ & $130 \pm 8^{a}$ & $144 \pm 10^{a}$ & n.s. & n.s. & n.s. \\
\hline Uric acid (mg/dl) & $5.3(1.5-12.1)^{c}$ & $5.6(3.0-11.8)^{c}$ & $5.6(3.3-6.9)^{c}$ & n.s. & n.s. & n.s. \\
\hline Albuminuria (mg/g) & $51(0-2237)^{c}$ & $33(0-1799)^{c}$ & $22(0-1656)^{c}$ & $<0.0001$ & $<0.0001$ & 0.03 \\
\hline Azoturia $(\mathrm{mg} / \mathrm{dl})$ & $1088 \pm 98^{a}$ & $753 \pm 78^{\mathrm{a}}$ & $603 \pm 67^{a}$ & 0.0001 & $<0.0001$ & 0.01 \\
\hline Sodiuria (mmol/l) & $61 \pm 5^{\mathrm{a}}$ & $58 \pm 4^{a}$ & $61 \pm 4^{\mathrm{a}}$ & n.s. & n.s. & n.s. \\
\hline Systolic blood pressure $(\mathrm{mm} \mathrm{Hg})$ & $140(105-224)^{c}$ & $130(100-210)^{c}$ & $130(100-185)^{\mathrm{c}}$ & 0.0002 & 0.0006 & n.s. \\
\hline
\end{tabular}


n.s. $=$ not significant. ${ }^{C}$ Data are expressed as median and range minimum-maximum. 
Table 3. Body-composition parameters at baseline (T0), after 3 weeks (T1) and after 6 weeks (T2) of low-protein diet

\begin{tabular}{|c|c|c|c|c|c|c|}
\hline Body-composition parameters ${ }^{\mathrm{a}}$ & TO & $T 1$ & $T 2$ & T0 versus $T 1, P$ & To versus $T 2, P$ & $T 1$ versus $T 2, P$ \\
\hline Weight (kg) & $71.8 \pm 2.1^{\mathrm{b}}$ & $70.6 \pm 1.9^{b}$ & $68.9 \pm 2.0^{b}$ & 0.0043 & 0.0044 & n.s. \\
\hline $\operatorname{BMI}\left(\mathrm{kg} / \mathrm{m}^{2}\right)$ & $27.8 \pm 0.8^{b}$ & $27.4 \pm 0.7^{b}$ & $26.6 \pm 0.7^{b}$ & 0.0052 & 0.0019 & 0.0367 \\
\hline $\mathrm{RZ}(\Omega)$ & $40(24-81)^{c}$ & $38(18-84)^{c}$ & $38(20-72)^{c}$ & n.s. & n.s. & n.s. \\
\hline $\operatorname{RX}(\Omega)$ & $467(254-609)^{c}$ & $457(278-729)^{c}$ & $455(255-599)^{c}$ & n.s. & n.s. & n.s. \\
\hline $\mathrm{PA}\left({ }^{\circ}\right)$ & $4.7(3.1-8.8)^{\mathrm{c}}$ & $4.8(2.7-9.6)^{c}$ & $4.3(3.0-7.6)^{c}$ & n.s. & 0.0001 & 0.0015 \\
\hline TBW (L) & $38.1(29.3-63.5)^{c}$ & $38.6(28.9-65.3)^{\mathrm{c}}$ & $38.8(28.1-68.9)^{c}$ & 0.0167 & 0.0003 & 0.0012 \\
\hline TBW (\%) & $55.0 \pm 1.1^{\mathrm{b}}$ & $56.0 \pm 1.1^{b}$ & $57.2 \pm 1.3^{\mathrm{b}}$ & 0.0312 & 0.0468 & 0.0088 \\
\hline FFM (kg) & $47.8(14.3-85.2)^{c}$ & $49.9(35.4-79.4)^{c}$ & $48.4(34.7-83.1)^{\mathrm{c}}$ & n.s. & n.s. & n.s. \\
\hline FFM (\%) & $68.5 \pm 1.7^{b}$ & $70.8 \pm 1.4^{b}$ & $72.1 \pm 1.7^{b}$ & n.s. & 0.0489 & n.s. \\
\hline $\mathrm{MM}(\mathrm{kg})$ & $27.6(20.3-57.0)^{c}$ & $27.9(20.3-50.9)^{\mathrm{c}}$ & $27.4(20.0-47.9)^{\mathrm{c}}$ & n.s. & 0.0005 & 0.0015 \\
\hline MM (\%) & $40.7(28.5-72.4)^{c}$ & $40.5(27.6-61.0)^{\mathrm{c}}$ & $39.8(29.8-54.9)^{\mathrm{c}}$ & n.s. & 0.0280 & 0.0408 \\
\hline FM $(\mathrm{kg})$ & $22.7 \pm 1.5^{\mathrm{b}}$ & $21.8 \pm 1.4^{b}$ & $19.9 \pm 1.4^{\mathrm{b}}$ & n.s. & n.s. & n.s. \\
\hline FM (\%) & $29.7 \pm 1.5^{b}$ & $29.2 \pm 1.4^{b}$ & $28.0 \pm 1.7^{b}$ & n.s. & n.s. & n.s. \\
\hline $\mathrm{BCM}(\mathrm{kg})$ & $21.8(15.6-46.1)^{c}$ & $21.5(15.0-48.8)^{c}$ & $20.4(15.0-37.4)^{c}$ & n.s. & 0.0005 & 0.0055 \\
\hline BCM (\%) & $46.8 \pm 1.2^{b}$ & $46.1 \pm 1.3^{b}$ & $43.8 \pm 1.1^{b}$ & n.s. & 0.005 & 0.0046 \\
\hline BCMI $\left(\mathrm{kg} / \mathrm{m}^{2}\right)$ & $8.9(5.8-17.1)^{c}$ & $8.5(5.6-15.3)^{c}$ & $7.9(6.1-14.6)^{c}$ & n.s. & 0.0005 & 0.0008 \\
\hline ECM $(k g)$ & $25.4(16.6-52.5)^{c}$ & $25.5(16.3-39.2)^{c}$ & $24.6(16.1-37.7)^{\mathrm{c}}$ & n.s. & n.s. & n.s. \\
\hline ECM (\%) & $53.2(26.5-66.4)^{c}$ & $52.7(32.2-70.0)^{\mathrm{c}}$ & $51.8(38.2-66.7)^{\mathrm{c}}$ & n.s. & n.s. & n.s. \\
\hline ECM/BCM & $1.1 \pm 0.4^{\mathrm{b}}$ & $1.3 \pm 0.4^{\mathrm{b}}$ & $1.3 \pm 0.4^{b}$ & 0.04 & 0.04 & n.s. \\
\hline
\end{tabular}

${ }^{a} B M I$, body mass index; RZ, resistance; RX, reactance; PA, phase angle; TBW, total body water; FFM, fat-free mass; MM, muscle mass; FM, fat mass; $B C M$, body cell mass; $\mathrm{BCMI}$, body cell mass index; $\mathrm{ECM}$, extracellular mass. $P<0.05$ is considered statistically significant; $\mathrm{n} . \mathrm{s} .=$ not significant. ${ }^{\mathrm{b}}$ Data are expressed as mean \pm S.E.M. 'Data are expressed as median and range minimum-maximum.
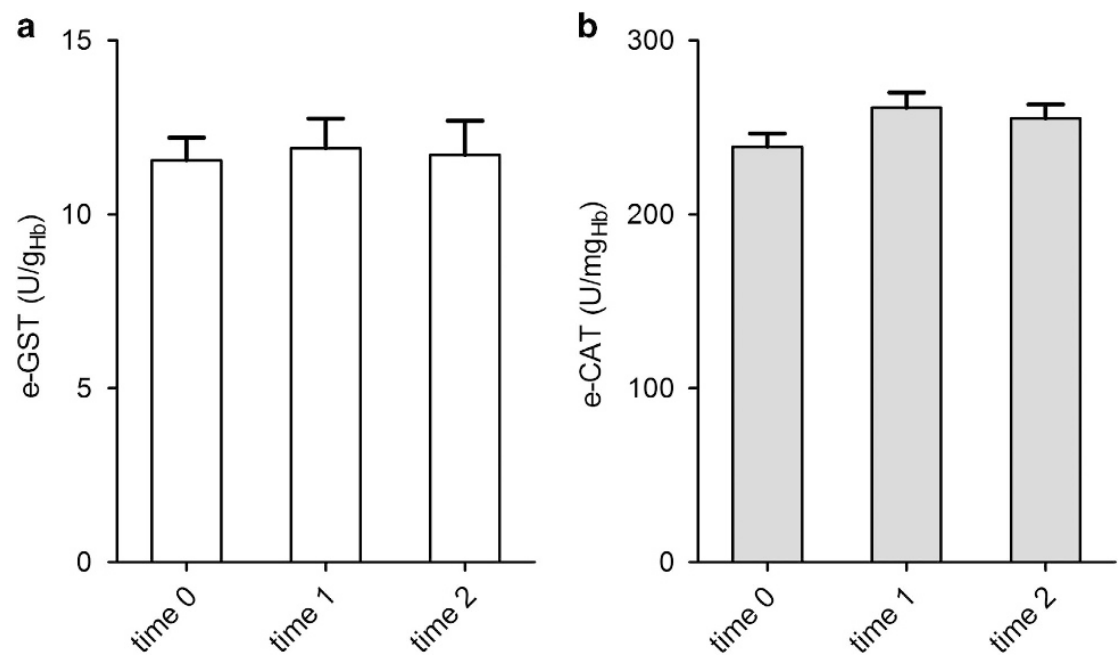

Figure 1. e-GST and e-CAT in patients during LPD. (a) e-GST after different time-points of diet treatment. Values are the mean of the measurements performed on 41 patients before diet (baseline) (time 0), 3 weeks of diet (time 1) and 6 weeks of diet (time 2). (b) e-CAT at different time-points of diet treatment. Values are the mean of the measurements performed on 41 patients before diet (baseline) (time 0 ), 3 weeks of diet (time 1) and 6 weeks of diet (time 2). Error bars are the S.E.M.

Although the LPD has been standardized as an important tool for the conservative therapy in CKD patients, currently there is a debate in literature about its real effectiveness.

In this study, we confirmed the benefits of this nutritional intervention in decreasing nitrogenous wastes and improving estimated glomerular filtration rate (GFR), as previous demonstrated. ${ }^{23}$ However, the protein restriction can be a further risk factor of malnutrition in these patients. In fact, we observed a significant reduction of biochemical parameters of nutritional status assessment such as serum albumin and total protein content. ${ }^{24-26}$ The reduction in serum albumin was observed only after 6 weeks of LPD because of its long half-life (about 20 days). Therefore, the reduced protein intake for the first 3 weeks showed no changes in the serum concentration of albumin. ${ }^{25}$
Traditionally, reduced serum albumin and decreased BMI are among the primary indicators of protein-energy malnutrition in uremic patients. ${ }^{12}$ In all time-points of our study, we observed a significant reduction of BMI.

The progressive malnutrition observed in CKD patients is associated with some markers of a chronic inflammation state that characterized the malnutrition-inflammation-atherosclerosis syndrome, inducing a vicious cycle where malnutrition, inflammation and atherosclerosis coexist. ${ }^{27}$ In this context, in addition to a deterioration of the nutritional status of the patients, we also found, after 6 weeks of LPD, a significant increase in inflammation parameters, evaluated by measuring CRP.

Our data suggest that LPD triggers a constant catabolic phase, which causes loss of protein from skeletal muscle. In fact, we 
observed a significant reduction of muscular mass at the end of the diet treatment. CKD per se is related to skeletal mass loss, causing the condition called 'uremic sarcopenia'. ${ }^{28-30}$ The etiology of uremic sarcopenia is not well understood, although several factors (such as inflammation, hormonal unbalances, malnutrition and metabolic acidosis) are involved.

Another index linked to malnourishment state, assessed by bioimpedance analysis, is the PA. ${ }^{22} \mathrm{~A}$ substantial and significant decrease of PA was showed during patients' diet treatment. The PA is used as an indicator of cellular density; a low PA is associated to the damage of cell's membrane and their impaired function. Actually, in literature, PA is negatively related to survival in several pathological conditions such as cancer, uremia and HIV infection. ${ }^{31-33}$ The PA is an independent predictor of survival in hemodialysis patients. ${ }^{34}$ An interesting study on PD patients showed that PA could be considered as an independent prognosis marker for survival and clinical improvement: the PD patients with $\mathrm{PA}>6.0^{\circ}$ had higher survival compared with those with PA values lower than $6.0^{\circ}$. $^{21}$ A PA reduction can reflect an increase in the ratio between extracellular and intracellular water or a decrease in BCM. $^{21}$

In the CKD patients, the assessment of the fluid state such as total body water and extracellular water and the evaluation of $B C M$ is crucial to verify the nutritional state. BCM represents the metabolically active cellular fraction of the body and, for this reason, it could be considered as a potentially sensitive indicator of lean tissue loss. ${ }^{35}$ In addition to BCM, lean tissue consists also in ECM. ECM/BCM ratio, which directly reflects the proportions between intracellular and extracellular space, is one of the most sensitive index of malnutrition. ${ }^{20}$ Avram et al. ${ }^{20}$ had demonstrated that an increased ECM/BCM ratio was considered a negative independent predictor index of survival in PD patients. Malnutrition features, characterized by a pronounced depletion of $\mathrm{BCM}$, with a greater ECM/BCM ratio due to the lack of functional muscle mass, was observed, for example, in HIV patients and reported as an early marker of malnutrition. ${ }^{36}$

In this study, we also observed a significant decrease of systolic blood pressure (BP), related with the restriction of the sodium in the diet, according to guidelines maintaining sodium intake $<2$ g/day. ${ }^{37}$ It was demonstrated that arterial hypertension and CKD are closely associated. In fact, BP typically arises when renal function is compromised, and induces the progression of kidney disease. ${ }^{38}$ Experimental animal models have shown that arterial hypertension causes kidney damage and decreases the kidney's ability to remove sodium. ${ }^{39}$ High dietary salt intake not only exacerbates arterial hypertension in nephropathic patients, but also has the potential to directly aggravate kidney dysfunction. In a Cochrane database systemic review, it was demonstrated that on reducing salt intake in CKD patients, there was a significant decrease of systolic and diastolic blood pressure. ${ }^{40}$

Interestingly, e-GST and e-CAT levels remained stable during the period of the study. This is a strong indication that toxins and oxidative stress inducers did not increase during the LPD. The level of e-GST in all patients before the diet was high and corresponded to the one found previously in other CKD stage IV patients. ${ }^{15,16,41}$ This finding confirms a persistent blood toxicity status during the LPD even if a weak renal function improvement was achieved.

\section{CONCLUSION}

In this study, we confirmed, coherently to the literature, that the LPD induces an improvement of the renal function, but at the same time, it contributes of the state of malnutrition usually observed in CKD patients.

The time limit of LPD did not allow us to evaluate a significant reduction of muscle mass, which is one of the pathognomonic criteria of uremic sarcopenia. Therefore, additional and prolonged studies will be needed to corroborate our hypothesis.

\section{SUBJECTS AND METHODS}

A total of 41 patients ( 22 males and 19 females), aged $73 \pm 14$ years, were recruited from the Department of Internal Medicine, Hypertension and Nephrology Unit, "Tor Vergata" University Hospital and Haemodyalisis and Nutrition Service, 'Nuova Clinica Annunziatella', Rome (Italy) according to the level of kidney function (Table 1).

The selected patients had a mean GFR of $23 \pm 1 \mathrm{ml} / \mathrm{min}$ corresponding to stages IIIb/IV according to K-DIGO guidelines. ${ }^{37}$

The primary causes of renal failure were: chronic glomerulonephritis (32\%), nephroangiosclerosis (58\%), chronic pyelonephritis and interstitial nephropathy (2\%), autosomal dominant polycystic kidney disease (2\%) and other causes $(\sim 5 \%)$ (Table 1). Exclusion criteria were: corticosteroid treatment, cancer, pregnancy and nursing, and immunological or autoimmune diseases except type II diabetes. All patients were managed with standard diet conservative treatment (LPD) according to (Italian Society of Nephrology) SIN. ${ }^{42}$ Controls were carried out at baseline (TO), after 3 weeks (T1) and after 6 weeks (T2). All the subjects provided a signed consensus at the enrollment, according to a protocol previously approved by the 'Tor Vergata' University Medical Ethical Committee, Rome, Italy.

\section{Low protein diet (LPD)}

In CKD, nutritional therapy has the aim to reduce intake of proteins, phosphorus, potassium and sodium, preserving an adequate energy intake. In CKD patients, the energy ingested is a crucial aspect of diet treatment. In fact, neutral or positive nitrogen balance normally requires adequate energy intake and poor energy intake may directly result in protein wasting. ${ }^{11}$ The daily energy intake is aimed at $30 / 35 \mathrm{kcal}$ per kilogram ideal body weight per day. ${ }^{8,9,42}$ From the time of enrollment (T0) to the next 6 weeks, patients followed a diet with controlled protein intake (recommended dietary allowance $0.7 \mathrm{~g}$ per kilogram ideal body weight per day of protein) and low-phosphorus intake (8-12 mg/g of protein). The restriction of potassium intake varies according to blood values, usually about 8-17 mg/kg/day, sodium intake $<2 \mathrm{~g} /$ day and calcium intake $<2 \mathrm{~g} /$ day.

The macronutrient composition of the diet therapy was: carbohydrates, $50-60 \% \mathrm{kcal} /$ day; proteins, $14 \% \mathrm{kcal} / \mathrm{day}$; total fat, $30 \% \mathrm{kcal} /$ day (saturated fat $<7 \% \mathrm{kcal} /$ day; polyunsaturated fatty acids, $10-20 \% \mathrm{kcal} / \mathrm{day}$; monounsaturated fatty acids, $10-20 \% \mathrm{kcal} /$ day; cholesterol consumption $<300 \mathrm{mg} /$ day), $15-20 \mathrm{~g}$ of fiber, folic acid $200-300 \mathrm{mcg}$. In the diet plan, we have used 'non proteic' (commercially available) carbohydrates in order to replace cereal foods (containing protein with low biological value) with similar products but with a low fat content and constantly controlled protein, sodium, potassium, tyrosine and phenylalanine. They also include inulin, a soluble dietary fiber. No alcoholic beverages were allowed.

The plan for each subject was obtained from a dietetic software package (Dietosystem, DS Medica, Milan, Italy).

\section{Anthropometric measurements}

After 12-h overnight fast, anthropometric measurements were performed on subjects in underwear without clothes and shoes. According to standard methods, the body weight $(\mathrm{kg})$ was measured to the nearest $0.01 \mathrm{~kg}$, using an accurate balance scale (Invernizzi, Rome, Italy). ${ }^{43}$ Height (m) was measured using a stadiometer to the nearest $0.1 \mathrm{~cm}$ (Invernizzi), BMI was calculated according to Quetelet Index (calculated as body weight divided by height squared $\left(\mathrm{kg} / \mathrm{m}^{2}\right)$ ).

\section{Bioelectrical impedance analysis}

Resistance, reactance, impedance and PA at $50 \mathrm{kHz}$ frequency were measured using bioelectrical impedance analysis (BIA 101S, Akern/RIL System, Florence, Italy).

The total body analysis allows the assessment of nutritional status and body fluids according to a bi-compartmental model. Bioelectrical impedance analysis is a safe, low-cost, noninvasive, rapid method for the assessment of body composition, displaying a great potential if used for epidemiological and clinical studies. Measurements were taken on left side of the body, with injection and sensor electrodes placed on the hand and foot in reference position. 
Total body water, intracellular water, extracellular water, BCM, fat mass and fat-free mass are estimated using the manufacturer's equations. ${ }^{44}$

\section{GFR estimation}

The estimated GFR was calculated using the CKD epidemiology collaboration (CKD-EPI) formula. ${ }^{45}$

\section{Blood pressure measurement}

Systolic and diastolic blood pressures were registered during each visit and defined as the average of two measurements 1 min apart, with 5 min rest before the first measurement.

\section{Analysis of blood samples}

Early morning blood samples were taken from each patient for biochemical screening test after a 12-h overnight fasting. Blood samples were collected into sterile tubes containing ethylenediaminetetraacetic acid (Vacutainer, BD, Plymouth, UK), via venipuncture from the antecubital vein. All materials were immediately placed on ice and plasma was separated by centrifugation at $1600 \times g$ for $10 \mathrm{~min}$ at $4{ }^{\circ} \mathrm{C}$. We measured serum lipid profile that included plasma total cholesterol, high-density lipoprotein cholesterol, low-density lipoprotein-cholesterol and triglyceride concentrations; for kidney function, we measured creatinine, azotemia and albumin, CRP, erythrocyte sedimentation rate, GST, e-CAT activity, uric acid and serum and urinary electrolytes (potassium, phosphorus, sodium, calcium, azoturia, sodiuria and albuminuria).

For determination of C-reactive protein, a nephelometric assay was used (BN IITM Nephelometer and PROTIS program, Simens Healtcare Diagnostic Milan, Italy).

The lipid profile that included total cholesterol (TC), high-density lipoprotein cholesterol, low-density lipoprotein cholesterol and triglyceride was determined through standard enzymatic colorimetric techniques (Roche modular P800, Roche diagnostics, Indianapolis, IN, USA), according to the manufacturer's procedures, with reagents provided by the same company.

All other parameters were analyzed according to standard techniques by the accredited Clinical Chemical Laboratories of the 'Tor Vergata' Policlinico (PTV) Rome, Italy.

\section{Chemicals and reagents}

Glutathione, 1-chloro-2,4-dinitrobenzene, ethylenediaminetetraacetic acid, $\mathrm{H}_{2} \mathrm{O}_{2}$ and all other reagents were purchased from Sigma-Aldrich (St Louis, $\mathrm{MO}, \mathrm{USA}$ ) and used without further purification.

\section{Erythrocyte glutathione transferase (e-GST) activity}

e-GST activity was determined with a spectrophotometric assay at $340 \mathrm{~nm}$ $\left(37^{\circ} \mathrm{C}\right)$, using an Uvikon 941 Plus spectrophotometer (Kontron Instruments, Watford, Herts, UK). Briefly, one volume $(40 \mu \mathrm{l})$ of whole blood was diluted in 25 volumes $(1 \mathrm{ml})$ of bi-distilled water causing red blood cell hemolysis. After $2 \mathrm{~min}, 0.1 \mathrm{ml}$ were diluted to a final volume of $1 \mathrm{ml}$ containing $1 \mathrm{mM}$ glutathione, $1 \mathrm{mM}$ 1-chloro-2,4-dinitrobenzene in $0.1 \mathrm{M}$ potassium phosphate buffer, $\mathrm{pH} 6.5$ according to the standard procedure of Habig and coworkers. ${ }^{46}$ Results were expressed as enzyme units (U) per gram of hemoglobin $(\mathrm{Hb})(\mathrm{U} / \mathrm{gHb})$ : one unit represents the amount of enzyme that catalyzes the conjugation of 1 micromole of glutathione to 1-chloro-2,4dinitrobenzene in $1 \mathrm{~min}$ at $37^{\circ} \mathrm{C} .{ }^{41}$

\section{Erythrocyte catalase (e-CAT) activity}

e-CAT activity was determined with a spectrophotometric assay at $240 \mathrm{~nm}$ $\left(25^{\circ} \mathrm{C}\right.$ ), using a Kontron Uvikon 941 Plus spectrophotometer (Kontron Instruments). One volume of $5 \mu \mathrm{l}$ of hemolyzed blood was diluted in $1 \mathrm{ml}$ of potassium phosphate buffer $0.05 \mathrm{M} \mathrm{pH} 7.0$ with ethylenediaminetetraacetic acid $0.1 \mathrm{mM}$, and finally $10 \mathrm{ul}$ of $\mathrm{H}_{2} \mathrm{O}_{2} 1 \mathrm{M}$ according to the standard procedure of Beers and Sizer. ${ }^{47}$ Results were expressed as enzyme units $(\mathrm{U})$ per gram of $\mathrm{Hb}(\mathrm{U} / \mathrm{gHb})$ : one unit represents the amount of enzyme that catalyzes the decomposition of 1 micromole of $\mathrm{H}_{2} \mathrm{O}_{2}$ in $1 \mathrm{~min}$ at $25^{\circ} \mathrm{C}$.

\section{Statistical analysis}

Data are represented as means \pm standard error of the mean (S.E.M.). All continuous variables were checked for normality using KolmogorovSmirnov test. Differences between baselines and final values were tested used paired samples $t$-test and Mann-Whitney test, as indicated The minimal level of significance of the differences was fixed at $P \leq 0.05$. Statistical analysis was performed using computer software packaged (SPSS for Windows version 13.0, SPSS, Chicago, IL, USA and Stata version 12.1, StataCorp, TX, USA).

\section{ABBREVIATIONS}

CKD, chronic kidney disease; LPD, low-protein diet; K-DIGO, kidney- disease improving global outcomes; PD, peritoneal dialysis; NHANES, national heart and nutrition examination survey; e-GST, erythrocyte glutathione Stransferase; e-CAT, erythrocyte catalase; CRP, C- reactive protein; $\mathrm{BMI}$, body mass index; $\mathrm{BCM}$, body cell mass; $\mathrm{BCMl}$, body cell mass index; $\mathrm{ECM}$ extracellular mass; PA, phase angle; GFR, glomerular filtration rate; $\mathrm{BP}$, blood pressure; SIN, Italian society of nephrology; CKD-EPI formula, chronic kidney disease epidemiology collaboration formula; TC, total cholesterol; S.E.M., standard error of the mean

\section{ACKNOWLEDGEMENTS}

We thank Dr Maria Silvia Borzacchi and Professor Simone Manca di Villahermosa for the clinical assistance.

\section{COMPETING INTERESTS}

The authors declare no conflict of interest.

\section{REFERENCES}

1 Arora $\mathrm{P}$, Vasa $\mathrm{P}$, Brenner D, Iglar K, McFarlane $\mathrm{P}$, Morrison $\mathrm{H}$ et al. Prevalence estimates of chronic kidney disease in Canada: results of a nationally representative survey. CMAJ 2013; 185: E417-E423.

2 Coresh MD J, Selvin E, Stevens LA, Manzi J, Kusek JW, Eggers P et al. Prevalence of chronic kidney disease in the United States. JAMA 2007; 298: 2038-2047.

3 U.S. Renal Data System. USRDS 2012 annual data report: atlas of chronic kidney disease and end-stage renal disease in the United States 2012, National Institutes of Health, National Institute of Diabetes and Digestive and Kidney Diseases: Bethesda, MD, USA.

4 Gambaro G, Yabarek T, Graziani MS, Gemelli A, Abaterusso C, Frigo AC et al. Prevalence of CKD in northeastern Italy: results of the INCIPE study and comparison with NHANES. Clin J Am Soc Nephrol 2010; 5: 1946-1953.

5 Di Daniele N, Petramala L, Di Renzo L, Sarlo F, Della Roca DG, Rizzo M et al. Body composition changes and cardiometabolic benefits of balanced Italian Mediterranean Diet in obese patients with metabolic syndrome. Acta Diabetologica 2013; 50: 409-416.

6 Andreoli A, Lauro S, Di Daniele N, Sorge R, Celi M, Volpe SL. Effect of a moderately hypoenergetic Mediterranean diet and exercise program on body cell mass and cardiovascular risk factors in obese women. Eur J Clin Nutr 2008; 62: 892-897.

7 Mohamed El, Maiolo C, lacopino L, Pepe M, Di Daniele N, De Lorenzo A. The impact of body-weight components on forced spirometry in healthy Italians. Lung 2002; 180: 149-159.

8 Fouque D, Laville M. Low protein diets for chronic kidney disease in non diabetic adults. Cochrane Database Syst Rev 2009; (3): CD001892.

9 Giovannetti S, Maggiore Q. a low nitrogen diet with protein of high biological value for severe chronic uraemia. Lancet 1964; i: 1000.

10 Ikziler TA. Dietary protein restriction: the debate continues. Am J Kidney Disease 2009; 53: 189-19.

11 Menon V, Kopple JD, Wang X, Beck GJ, Collins AJ, Kusek JW et al. Effect of a very low protein diet on outcomes: long term follow-up of the modification of diet in renal disease (MDRD) Study. Am J Kidney Dis 2009 53: 208-217.

12 Kovesdy CP, Kopple JD, Kalantar-Zadeh K. Management of protein energy wasting in non dialysis-dependent chronic kidney disease: reconciling low protein intake with nutritional therapy. Am J Clin Nutrition 2013; 97: 1163-1177.

13 Kato A, Takita T, Furuhashi M, Maruyama Y, Hishida A. Comparison of serum albumin, $C$ reactive protein and carotid atherosclerosis as predictors of 10-year mortality in hemodialysis patients. Hemodial Int 2010; 14: 226-232.

14 Kalantar-Zadeh K, Kovesdy CP, Derose SF, Horwich TB, Fonarow GC. Racial and survival paradoxes in chronic kidney disease. Nat Clin Pract Nephrol 2007; 3: 493-506.

15 Noce A, Fabrini R, Dessì M, Bocedi A, Santini S, Rovella V et al. Erythrocyte glutathione transferase activity: a possible early biomarker for blood toxicity in uremic diabetic patients. Acta Diabetol 2014; 51: 219-224.

16 Noce A, Fabrini R, Bocedi A, Di Daniele N. Erythrocyte glutathione transferase in uremic diabetic patients: additional data. Acta Diabetol 2015; 52: 813-815. 
17 Noce A, Ferrannini M, Fabrini R, Bocedi A, Dessì M, Galli F et al. Erythrocyte glutathione transferase: a new biomarker for hemodialysis adequacy, overcoming the Kt/V(urea) dogma? Cell Death Dis 2012; 3: e377.

18 Lai S, Molfino A, Coppola B, De Leo S, Tommasi V, Galani A et al. Effect of personalized dietary intervention on nutritional metabolic and vascular indices in patients with Chronic kidney Disease. Eur Rev Med Pharmacol Sci 2015; 19: 3351-3359.

19 Talluri T, Liedtke RJ, Evangelisti A, Talluri J, Maggia G. Fat-free mass qualitative assessment with bioelectric impedance analysis (BIA). Ann NY Acad Sci 1999; 873: 94-98.

20 Avram MM, Fein PA, Borawski C, Chattopadhyay J, Madtza B. Extracellular mass/ body cell mass ratio is an independent predictor of survival in peritoneal dialysis patients. Kidney Int 2010; 78: S37-S40.

21 Mushnick R, Fein PA, Mittman N, Goel N, Chattopadhyay J, Avram MM. Relationship of bioelectrical impedance parameters to nutrition and survival in peritoneal dialysis patients. Kidney Int 2003; 64: S53-S56.

22 Gupta D, Lammersfeld CA, Burrows JL, Dahlk SL, Vashi PG, Grutsch JF et al. Bioelectrical impedance phase angle in clinical practice: implications for prognosis in advanced colorectal cancer. Am J Clin Nutr 2004; 80: 1634-1638.

23 Kasiske BL, Lakatua JD, Ma JZ, Louis TA. A meta-analysis of the effects of dietary protein restriction on the rate of decline in renal function. Am J Kidney Dis 1998; 31: 954-961.

24 Gama-Axelsson T, Heimburger O, Stenvinkel P, Barany P, Lindholm B, Qureshi AR. Serum Albumin as Predictor of Nutritional Status in Patients with ESRD. Clin J Am Soc Nephrol 2012; 7: 1446-1453.

25 Dessì M, Noce A, Agnoli A, De Angelis S, Fuiano L, Tozzo C et al. The usefulness of the prognostic inflammatory and nutritional index (PINI) in a haemodialysis population. Nutr Metab Cardiovasc Dis 2009; 19: 811-815.

26 Zyga S, Christopoulou G, Malliarou M. Malnutrition-inflammation-atherosclerosis syndrome in patients with end-stage renal disease of renal. $J$ Ren Care 2011; 37: 12-15.

27 Stenvinkel P, Carrero JJ, von Walden F, Ikizler TA, Nader GA. Muscle wasting in end-stage renal disease promulgates premature death: established, emerging and potential novel treatment strategies. Nephrol Dial Transplant 2015; 0: 1-8.

28 Maggiore Q, Nigrelli S, Ciccarelli C, Grimaldi C, Rossi GA, Michelassi C. Nutritional and prognostic correlates of bioimpedance indexes in hemodialysis patients. Kidney Int 1996; 50: 2103-2108.

29 Sbraccia P, D'Adamo M, Leonetti F, Buongiorno A, Silecchia G, Basso MS et al. Relationship between plasma free fatty acids and uncoupling protein-3 gene expression in skeletal muscle of obese subjects: in vitro evidence of a causal link. Clin Endocrinol (Oxf) 2002; 57: 199-207.

30 lantorno M, Campia U, Di Daniele N, Nistico S, Forleo GB, Cardillo C et al. Obesity, inflammation and endothelial dysfunction. J Biol Regul Homeost Agents 2014; 28: 169-176.

31 Fein PA, Gundumalla G, Jorden A, Matza B, Chattopadhyay J, Avram MM. Usefulness of bioelectrical impedance analysis in monitoring nutrition status and survival of peritoneal dialysis patients. Adv Perit Dial 2002; 18: 195-199.

32 Schwenk A, Beisenherz A, Romer K, Kremer G, Salzberger B, Elia M. Phase angle from bioelectrical impedance analysis remains an independent predictive marker in HIV-infected patients in the era of highly active antriretroviral treatment. Am J Clin Nutr 2000; 72: 496-501.
33 Schinzari F, Tesauro M, Rovella V, Di Daniele N, Mores N, Veneziani A et al. Leptin stimulates both endothelin-1 and nitric oxide activity in lean subjects but not in patients with obesity-related metabolic syndrome. J Clin Endocrinol Metab 2013; 98: $1235-1241$.

34 Maggiore Q, Nigrelli S, Ciccarelli C, Grimani DC, Rossi GA, Michelassi C. Nutritional and prognostic correlates of bioimpedance indexes in hemodialysis patients. Kidney Int 1996; 50: 2103-2108.

35 Rymarz A, Bartoszewicz Z, Szamotulska K, Niemczyk S. The associations between body cell mass and nutritional and inflammatory markers in patients with chronic kidney disease and in subjects without kidney disease. J Ren Nutr 2016; 26: 87-92.

36 Ott M, Lembcke B, Fischer H, Jäger R, Polat H, Geier H et al. Early changes of body composition in human immune deficiency in virus- infected patients: tetrapolar body impedance analysis indicates significant malnutrition. Am J Clin Nutr 1993; 57: 15-19.

$37 \mathrm{KDIGO}$. Clinical practice guideline for the evaluation and management of chronic kidney disease. Kidney Int Supp/ 2012; 2013: 3.

38 Judd E, Calhoun DA. Management of hypertension in CKD: beyond the guidelines. Adv Chronic Kidney Dis 2015; 22: 116-122.

39 Ying WZ, Sanders PW. Dietary salt modulates renal production of transforming growth factor-beta in rats. Am J Physiol 1998; 274: F635-F641.

40 McMahon EJ, Campbell KL, Bauer JD, Mudge DW. Altered dietary salt intake for people with chronic kidney disease. Cochrane Database Syst Rev 2015; (2): CD010070.

41 Dessì M, Noce A, Dawood KF, Galli F, Taccone-Gallucci M, Fabrini R et al. Erythrocyte glutathione transferase: a potential new biomarker in chronic kidney diseases which correlates with plasma homocysteine. Amino Acids 2012; 43: 347-354.

42 Quintaliani G, Di lorio BR, Bellizzi V, Cupisti A, Oldrizzi L, Santoro D. Terapia nutrizionale nell'IRC in fase conservativa: suggerimenti di pratica clinica e di applicazione delle Linee Guida. G Ital Nefrol 2013; 30, (S59)-ISSN 1724-5590.

43 Lohman TG, Roche AF, Martorell R. Anthropometric Standardization Reference Manual. Human Kinetics Press: Champaing, IL, USA, 1998, pp 121-133.

44 De Lorenzo A, Candeloro N, Andreoli A, Durenberg P. Determination on intracellular water by multifrequency bioelectrical impedance. Ann Nutr Metab 1995; 39: 177-184.

45 Florkowski CM, Chew-Harris JS. Methods of estimating GFR-different equations including CKD-EPI. Clin Biochem Rev 2011; 32: 75-79.

46 Habig WH, Pabst MJ, Jakoby WB. Glutathione S-transferases. The first enzymatic step in mercapturic acid formation. J Biol Chem 1974; 249: 7130-7139.

47 Beers RF, Sizer IW. A spectrophotometric method for measuring the breakdown of hydrogen peroxide by catalase. J Biol Chem 1952; 195: 133-140.

This work is licensed under a Creative Commons Attribution 4.0 International License. The images or other third party material in this article are included in the article's Creative Commons license, unless indicated otherwise in the credit line; if the material is not included under the Creative Commons license, users will need to obtain permission from the license holder to reproduce the material. To view a copy of this license, visit http://creativecommons.org/licenses/ by/4.0/ 